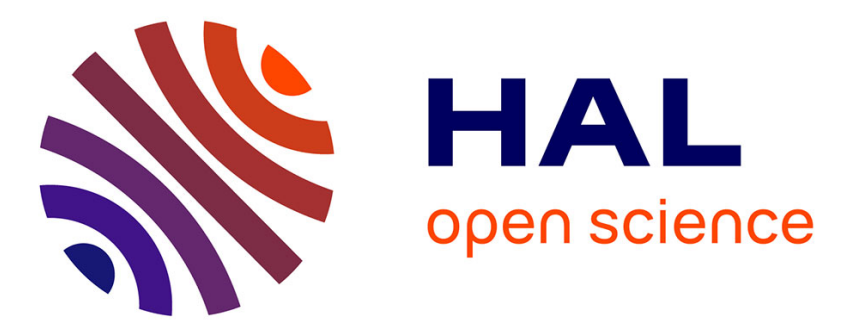

\title{
The anisotropic temperature rise on wood surfaces during adsorption measured by thermal imaging
}

Anna Dupleix, Tien van Nguyen, Katja Vahtikari, Mark Hughes

\section{To cite this version:}

Anna Dupleix, Tien van Nguyen, Katja Vahtikari, Mark Hughes. The anisotropic temperature rise on wood surfaces during adsorption measured by thermal imaging. Wood Science and Technology, inPress, 10.1007/s00226-017-0968-8 . hal-01669049

\section{HAL Id: hal-01669049 \\ https://hal.science/hal-01669049}

Submitted on 20 Dec 2017

HAL is a multi-disciplinary open access archive for the deposit and dissemination of scientific research documents, whether they are published or not. The documents may come from teaching and research institutions in France or abroad, or from public or private research centers.
L'archive ouverte pluridisciplinaire HAL, est destinée au dépôt et à la diffusion de documents scientifiques de niveau recherche, publiés ou non, émanant des établissements d'enseignement et de recherche français ou étrangers, des laboratoires publics ou privés. 


\title{
The anisotropic temperature rise on wood surfaces during adsorption measured by thermal imaging
}

\author{
Anna Dupleix ${ }^{1}$ Tien Van Nguyen ${ }^{1}$ Katja Vahtikari ${ }^{1} \cdot$ \\ Mark Hughes ${ }^{1}$
}

\begin{abstract}
The aim of the work reported herein was to investigate anisotropy in the temperature rise occurring on the surface of Scots pine (Pinus sylvestris L.) during adsorption. The temperature increase on the transverse, radial and tangential surfaces of small wood specimens during adsorption was measured by thermal imaging. The experiments were conducted in a purpose-built humidity chamber facilitating the accurate control of the internal relative humidity (RH). It was found that the temperature rise on initially oven-dry wood surfaces exposed to a RH of $95 \%$ was anisotropic, with a maximum temperature increase of around $4{ }^{\circ} \mathrm{C}$ occurring on the transverse surface and around $1{ }^{\circ} \mathrm{C}$ on both the radial and tangential surfaces. Additionally, it was observed that the technique reported can be used to accurately measure the temperature change arising from sorption, thus providing reliable information about the behaviour of wood. This information is vital if the effects of the enthalpy change occurring during water vapour sorption are to be correctly considered in building physics models and the potential to reduce energy consumption in buildings fully realised.
\end{abstract}

\section{Introduction}

\section{Background and objectives}

Wood is a plentiful and renewable material with low embodied energy that is already used extensively as a building construction material. In addition to its

Mark Hughes

mark.hughes@aalto.fi

1 Department of Bioproducts and Biosystems, School of Chemical Engineering, Aalto University, 00076 Espoo, Finland 
excellent structural properties, it can act as moisture and thermal buffer (Kraniotis et al. 2016), and this ability can lead to reduced energy demand by helping to passively control the internal relative humidity $(\mathrm{RH})$ of a living space (Osanyintola and Simonson 2006; Holcroft and Shea 2014). This would offer the potential to reduce the overall energy consumption of buildings both directly, through lower space heating/cooling needs, and indirectly by reducing the requirements for heating, ventilating and air-conditioning (HVAC) equipment.

When wood adsorbs water vapour from the surrounding air, it is accompanied by a release of heat - the heat of sorption-during the phase change from vapour in the air to water adsorbed in the cell wall (Skaar 1988); conversely, when desorption occurs, heat is required. This change in enthalpy can result in a change in surface temperature. Brueckner et al. (2012), for example, investigated the surface temperature change during adsorption in untreated spruce wood panels, finding that a surface temperature increase of $2{ }^{\circ} \mathrm{C}$ occurred when the ambient relative humidity (RH) rose from 20 to $90 \%$. Recently, the question of whether this enthalpy change could be used to reduce the energy consumption of buildings, has become the subject of speculation and research (Kraniotis et al. 2016). Nevertheless, for it to be correctly considered in building physics models, accurate data about the temperature changes in wood arising from sorption are required, and this forms the subject matter of the study reported herein.

Many of the properties of wood are known to be highly anisotropic, and this includes moisture transport. For example, the moisture diffusion coefficient of dry pine is approximately 60 times greater in the longitudinal direction than the transverse direction (Siau 1984). This implies that heat may be evolved more rapidly as moisture is adsorbed on the transverse surface of wood, which might also result in a more significant temperature rise on this surface. However, it should be noted that thermal conduction is around 1.5 times greater in the axial direction than in the transverse direction (Suleiman et al. 1999), so this must be factored in as well. In most uses, such as internal wall panelling, the tangential or radial surfaces of wood are exposed to the surroundings; it is just possible that for mediating the internal climate of a room, it may be advantageous to expose the transverse surface. The aim of this study was therefore to investigate the degree of anisotropy in the temperature rise occurring on the transverse, radial and tangential surfaces of wood undergoing sorption.

\section{Physio-chemistry of sorption in wood}

According to Kollmann and Côté (1968), the total heat of sorption $\left(Q_{\mathrm{S}}\right)$ of wood is the overall heat released when a unit mass of wood at a particular moisture content adsorbs moisture up to the fibre saturation point (FSP), expressed as the unit mass of

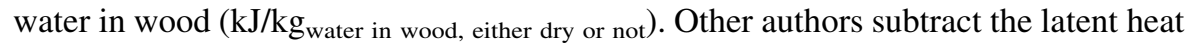
of condensation (or vaporisation) of free water at the same temperature, $\Delta H_{\text {cond }}$, taken to be $2443.9 \mathrm{~kJ} / \mathrm{kg}_{\text {water }}$ at $25^{\circ} \mathrm{C}$ (Marsh 1987), to obtain the net heat of sorption, which can be calculated for dry wood $\left(h_{\mathrm{S}}\right)$ or for wood at any higher moisture content $\left(q_{\mathrm{S}}\right)$. Thus, 
- At $0 \% \mathrm{MC}$, the heat released (kJ) is given by $Q_{\mathrm{S}}=h_{\mathrm{S}}+\Delta H_{\text {cond }}$ (Simón et al. 2015; Kraniotis et al. 2016) expressed as the unit mass of water in dry wood (kJ/ $\mathrm{kg}_{\text {water in dry wood); }}$;

- At higher moisture content (MC), the heat released $(\mathrm{kJ})$ is given by $Q_{\mathrm{S}}=q_{\mathrm{S}}+\Delta H_{\text {cond }}$ with $q_{\mathrm{S}}=f(\mathrm{~m})$ where $\mathrm{m}$ is the mass of water in wood (Skaar 1988) expressed as the unit mass of water in wood $\left(\mathrm{kJ} / \mathrm{kg}_{\text {water in wood }}\right.$ ).

According to the physio-chemical theory of water adsorption in wood (Avramidis 1997), water molecules are strongly attracted to the various hydrophilic chemical groups, principally hydroxyl $(\mathrm{OH})$ groups, naturally present in the wood cell wall constituents. This attraction leads the water molecules to hydrogen bond (H-bond) to sorption sites in the non-crystalline cell wall regions (Salmén 1997; Engelund et al. 2013; Perré 2015). Since the H-bonds formed between water molecules and the $\mathrm{OH}$ groups of the cell wall polymers are always stronger than the H-bonds of the liquid water molecules between them (Perré 2015), water molecules preferentially 'bind' to the wood rather than simply condense and form a liquid film over the wood substrate. If this was the case, the heat of sorption would equal the latent heat of vaporisation of water, $\Delta H_{\text {cond }}$ (Fig. 1). However, being more stable, bound water has a lower energy level than atmospheric water, $H_{\text {bound water }}<H_{\text {atmospheric water }}$ (Time 1998). Adsorption - in which atmospheric water vapour molecules become bound to the wood-is therefore exothermic (negative enthalpy), releasing energy in

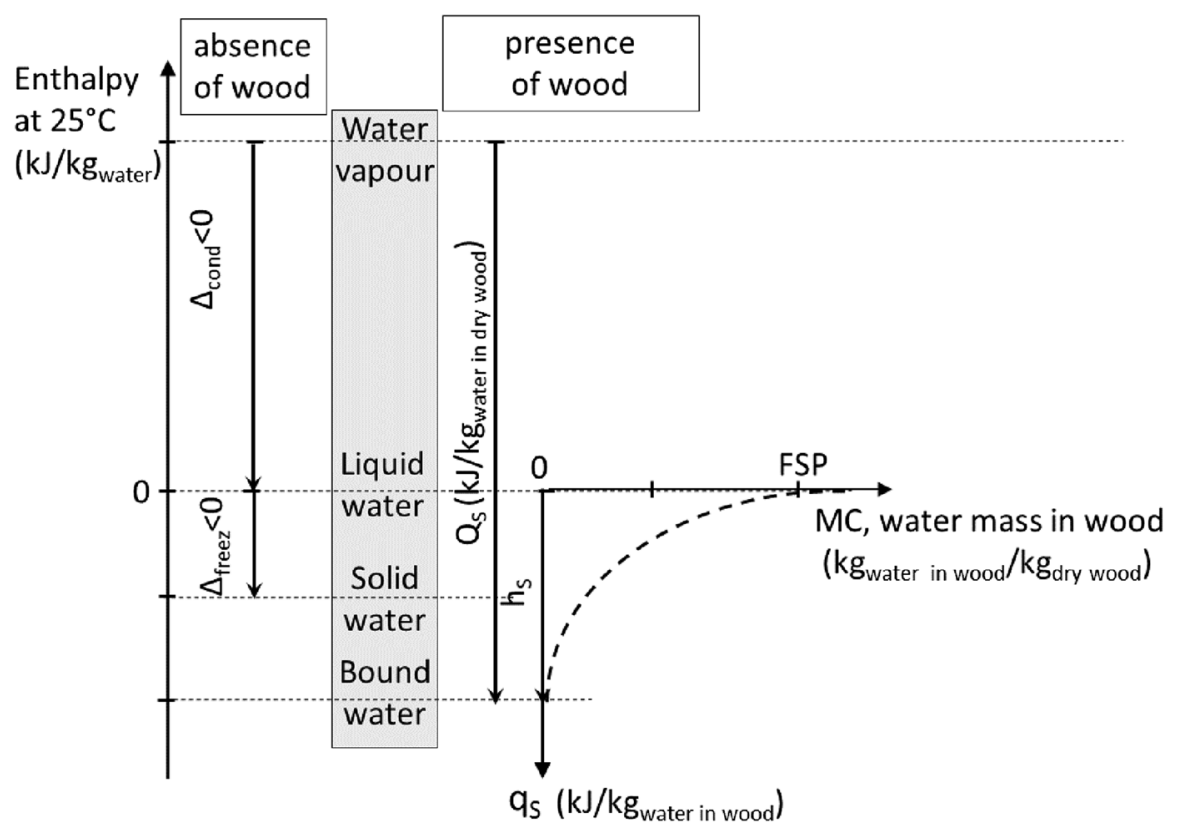

Fig. 1 In the absence of wood, the phase change of water from the gaseous to solid states releases an amount of energy equal to $\Delta H_{\text {cond }}+\Delta H_{\text {freez }}$, whilst in the presence of wood, the phase change of water from vapour to bound water states releases $\Delta H_{\text {cond }}+q_{\mathrm{s}}$ (or $h_{\mathrm{S}}$ for dry wood). Adapted from Time (1998) and Leuk et al. (2015) 
the form of heat: $\Delta H_{\text {sorption }}=\sum_{\text {hydrogen bonds }} H_{\text {bound water }}-\sum H_{\text {atmospheric water }}<0$. For Skaar (1988), the heat of sorption is the excess binding energy of water molecules 'bound' to the wood solid substrate over that of liquid water molecules between them. It is a direct measure of the amount of water 'bonded' to the cell wall and, according to the physio-chemical theory of water adsorption in wood (Avramidis 1997), it is an indirect measure of the number of sorption sites accessible in wood.

From Skaar's equations, heat of sorption decreases exponentially as wood MC increases, varying from circa $900 \mathrm{~kJ} / \mathrm{kg}_{\text {water in wood }}$ for oven-dry wood to zero when wood reaches FSP. For Avramidis (1997), this decrease is supported by the physio-chemical adsorption theory in which the binding energy of water to wood lowers when the moisture in wood increases. However, work done by Hofstetter et al. (2006) on native cellulose does not confirm this to be the case, calling into question whether the heat of sorption can be explained by binding energies alone (Engelund 2011). Regardless of the underlying mechanisms behind the heat of sorption phenomenon, the sorption of water in wood, resulting from a variation in $\mathrm{RH}$, leads to a change in the temperature which might be beneficially used to affect the overall energy balance of a building.

\section{Measuring surface temperature changes in wood}

Measuring the temperature rise on wood surfaces poses several problems. First of all, sorption takes place rapidly, and for this reason when measuring temperature change as a result of a change in $\mathrm{RH}$, the change in $\mathrm{RH}$ should be more or less instantaneous. Experimentally this is difficult to achieve, even in dedicated systems such as dynamic vapour sorption (DVS) apparatus, and leads to difficulties in data analysis (Hill et al. 2010). For this reason, a bespoke apparatus was designed and built for this work (see 'Experimental' section for details), which allows for stable internal temperature to be maintained whilst ensuring a rapid, though not instantaneous, change in the internal $\mathrm{RH}$. A second problem relates to the measurement of surface temperature. Traditional ways of measuring temperature rely on contact methods, such as thermocouples. These may either interfere with the sorption process if they are attached to the surface or may not measure the actual surface temperature if they are embedded in the wood material and, as such, they are not ideal for measuring surface temperature changes. Thermography on the other hand has reached a state of development where it has been used to measure the temperature on a variety of materials.

The quantitative use of thermal imaging requires knowledge of the emissivity of the material constituting the target in the spectral range of the infrared camera used to perform the image acquisition (Avdelidis and Moropoulou 2003; Barreira and de Freitas 2007). This physical quantity characterises the ability of a material to emit thermal radiation at particular wavelengths. This explains why literature values for wood emissivity have only been gathered from 7.5 to $13 \mu \mathrm{m}\left(769\right.$ to $\left.1333 \mathrm{~cm}^{-1}\right)$ which is within the spectral range of the infrared FLIR e60 camera used in this present work (FLIR 2013). Few literature values carefully specify the wood species, temperature and moisture content used during emissivity measurements (Table 1). 
Table 1 Comparison of experimental emissivity values reported for pine and other wood species (when known) in the literature in the spectral range $7.5-13 \mu \mathrm{m}$

\begin{tabular}{lllllll}
\hline $\begin{array}{l}\text { Spectral range } \\
(\mu \mathrm{m})\end{array}$ & $\begin{array}{l}\text { Temp. } \\
\left({ }^{\circ} \mathrm{C}\right)\end{array}$ & MC $(\%)$ & Wood species & Emissivity & Authors & $\begin{array}{l}\text { Median } \\
\text { values }\end{array}$ \\
\hline $7.5-13$ & 22 & N/A & Pine & 0.92 & Lopez et al. (2013) & $\mathbf{0 . 9 2}$ \\
$7.5-13$ & $20-25$ & $20-22$ & Spruce, Douglas-fir & $0.93-0.97$ & Dupleix et al. (2013) & $\mathbf{0 . 9 5}$ \\
$7.5-13$ & $20-25$ & 6468 & Beech, birch & $0.95-0.98$ & Dupleix et al. (2013) & $\mathbf{0 . 9 7}$ \\
Full spectrum & 20 & N/A & N/A & 0.90 & Gaussorgues (1999) & $\mathbf{0 . 9 0}$ \\
Mean & & & & & & $\mathbf{0 . 9 3}$ \\
COV $(\%)$ & & & & & & 2.7 \\
\hline
\end{tabular}

Values in bold typeface derive from calculation

However, the overall trends in the influence of temperature and moisture content can be summarised as follows: (1) dry wood behaves as a dielectric material; its emissivity decreases with temperature (Lopez et al. 2013; Gaussorgues 1999), (2) the emissivity of wood increases with its moisture content up to FSP at which point it reaches the emissivity of water (Kollmann and Côté 1968). Work done by Dupleix et al. (2013) confirms that, in the spectral range of interest 7.5-13 $\mu \mathrm{m}$, wood emissivity does not vary with moisture content above FSP.

\section{Materials and methods}

In the design of the experiments reported herein, special care was taken to maximise the precisions of the measurements (camera settings) and minimise uncertainties (temperature and humidity conditions inside the chamber, measurement protocol) in order to obtain as accurate values as possible in these delicate measurements.

\section{Experimental set-up}

\section{Specimen preparation}

Boards of Scots pine (Pinus sylvestris L.) obtained from a tree grown in southern Finland were used throughout. The specimens were cut consecutively from the same board, and they contained both heartwood and sapwood. The following denomination for the specimens is used hereinafter: 'radial' specimens refer to specimens in which the exposed surface is radial, i.e. they are cut in the longitudinal-tangential plane (L-T in Fig. 2b), 'tangential' specimens are specimens in which the exposed surface is tangential, i.e. the longitudinal-radial plane ( $\mathrm{L}-\mathrm{R}$ in Fig. $2 \mathrm{~b}$ ) and in 'transverse' specimens, the transverse surface is exposed, i.e. the tangential-radial plane (T-R in Fig. 2b). In order to limit structural differences, the 10 replicates tested were five pairs of 'mirror' samples. However, due to limitations on the amount of material, the transverse samples were not mirror samples but came from locations close to one another. The sample size of $50 \times 50 \times 25 \mathrm{~mm}^{3}$ 
(a)

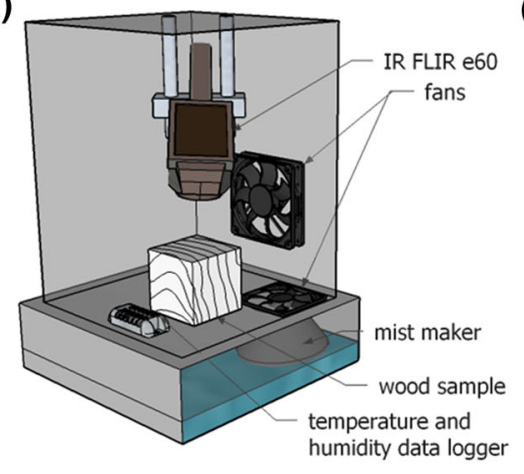

(b)



Fig. 2 a Experimental set-up showing (b) the three directions of wood ( $\mathrm{L}$ for longitudinal, $\mathrm{R}$ for radial and $\mathrm{T}$ for tangential) and the corresponding surfaces (radial $\mathrm{L}-\mathrm{R}$, tangential $\mathrm{L}-\mathrm{T}$ and transverse $\mathrm{T}-\mathrm{R}$ )

(length $\times$ width $\times$ height) was chosen so as to be as large as possible in order to avoid any edge effects affecting the region of interest of the camera display. This sample size also represented a compromise between the space available inside the humidity chamber (see 'Humidity chamber' section), the focal length of the IR camera $(195 \mathrm{~mm})$ and the desire to maintain a constant surface-to-volume ratio irrespective of the grain orientation.

\section{Humidity chamber}

A purpose-built humidity chamber (Fig. 2a) was constructed. It featured two fans, a mist maker and a water tank enabling a homogeneous and constant RH of up to $95 \%$ to be reached. The fans and mist maker were controlled by an Arduino Uno microcontroller board, which automatically adjusted the conditions until the set point value of the data logger placed inside the chamber was reached. All devices were controlled, and their measurements recorded as a function of time, through a LabVIEW $^{\circledR}$ interface. One fan was a basic model which could only be switched on or off according to the needs of the mist maker to reach the humidity set point value; the other fan, from Antec Tricool, revolved at constant speed (1600 rpm) during the experiments in order to ensure homogeneous conditions within the chamber. The dimensions of the chamber were $300 \times 300 \mathrm{~mm}^{2}$ (width $\times$ length), and the height was $600 \mathrm{~mm}$ with the tank and $400 \mathrm{~mm}$ without the tank. The front door was closed by magnets and, in addition, a thick transparent plastic film was used to cover the doorway to minimise disruption of the interior conditions when handling the samples placed inside. The humidity chamber was equipped with one Hygrofox $\mathrm{Mini}^{\circledR}$ data logger placed at the sample level-to record $\mathrm{RH}$ and temperature (accuracy: $\pm 3 \%$ and $\pm 0.4{ }^{\circ} \mathrm{C}$, respectively). The plastic cover of the data logger was removed to ensure better contact of the inner sensors with their surroundings. The chamber itself was located in a conditioning room stabilised at $65 \%$ and $23{ }^{\circ} \mathrm{C}$. 


\section{Camera}

A FLIR infrared (IR) camera e60 (uncooled microbolometer detector) was chosen for its compact format so that it would fit in the humidity chamber. The position of the thermal camera was adjusted to minimise changes to the camera angle of view and the distance between the camera and the measured surface. The distance between the camera and the specimen was chosen in order to minimise the (moist) air layer in between so as to reduce possible disturbances. The angle between the camera angle of view and the horizontal plane was set at around $25^{\circ}$ in order to reduce IR reflection from the camera lens and respect the limiting angle $\left(45^{\circ} / 50^{\circ}\right)$ advised by the camera manufacturers FLIR, above which the emissivity of materials such as wood starts to change (personal communication). The pertinent camera characteristics are summarised in Table 2, and further detailed information can be found in FLIR e-series datasheet (FLIR 2013).

\section{Measurement protocol}

\section{Specimens}

The specimens were covered on five faces with an Advance ${ }^{\circledR}$ aluminium tape previously tested for its ability to prevent any uptake of water vapour. Only the top face of the specimen was freely exposed to humidity when placed inside the chamber.

\section{Time}

The humidity chamber set point of $95 \% \mathrm{RH}$ is reached within a couple of minutes, but in the experiments, the chamber was stabilised for at least $1 \mathrm{~h}$ prior to commencing the measurements in order to minimise effects from any artificial temperature sources such as the fans and the camera motors. Allowing for the temperature to equilibrate was found to be extremely important since the surface temperature rise resulting from heat of sorption was of the order of a couple of degree Celsius.

\section{Reflective ambient temperature (RAT)}

RAT takes into account the parasitic radiation from the surroundings reflected by the measured surface. It is determined by recording the mean temperature of a mirror reflecting all incident radiation when the IR camera emissivity is set to 1 (a

Table 2 FLIR E60 IR camera specifications

\begin{tabular}{llll}
\hline Temperature range & -20 to $650{ }^{\circ} \mathrm{C}$ & Spectral range & $7.5-13 \mu \mathrm{m}$ \\
Thermal sensitivity & $<0.05{ }^{\circ} \mathrm{C}$ at $30{ }^{\circ} \mathrm{C}$ & Dimensions & $246 \times 97 \times 184 \mathrm{~mm}$ \\
Frame rate & $60 \mathrm{~Hz}$ maximum & Minimum focus distance & $195 \mathrm{~mm}$ \\
Exactitude/accuracy & $\pm 2 \%$ or $2{ }^{\circ} \mathrm{C}$ & Focal plane array & $240 \times 180$ pixels \\
\hline
\end{tabular}


mirror surface was obtained by covering the top face of a specimen with crumpled Advance ${ }^{\circledR}$ aluminium tape).

\section{Surface temperature rise}

The specimens were dried to $0 \% \mathrm{MC}$ in a fan-assisted oven at $103{ }^{\circ} \mathrm{C}$ for $24 \mathrm{~h}$. Upon removal from the oven, aluminium tape was quickly applied to 5 surfaces and a strip of black electrical tape (reference emissivity) applied to the exposed surface. The specimens were then immediately transferred to a desiccator $(0 \% \mathrm{RH})$ where they were cooled to room temperature over silica gel for an additional $24 \mathrm{~h}$. The open surface of the specimens was then covered with a 'lid' made out of aluminium foil and placed inside the humidity chamber about $1 \mathrm{~h}$ before the experiment began to ensure that its temperature equilibrated with that of the humidity chamber. The sample was placed inside the humidity chamber so that it was in the field of view of the IR camera. The camera recording began when the aluminium foil 'lid' was removed. This protocol ensures that the surface temperature changes on the wood specimen are recorded immediately the (dry) wood surface comes into contact with the high RH of the chamber; since the temperature and RH remain constant inside the chamber (Fig. 3b). The temperature and $\mathrm{RH}$ conditions inside the humidity chamber were considered to be ostensibly constant at $22.7 \pm 0.4{ }^{\circ} \mathrm{C}$ and $95 \% \pm 3 \%$ according to the records from the data logger plotted in Fig. $3 \mathrm{~b}$ for one experiment, but being representative of all others. Throughout the test there was no 'lag' during which the conditions stabilise. This is important when it comes to detecting the rate of heat evolution and temperature rise and to the authors' knowledge this level of control has not been employed previously.

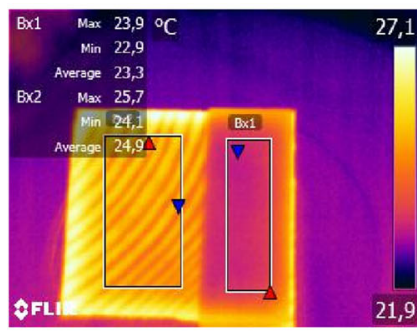

(a)

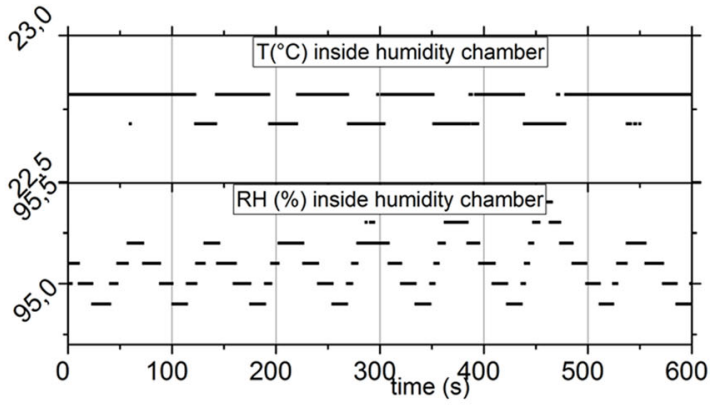

(b)

Fig. 3 a Snapshot of a radial surface taken with the IR camera as recorded during the experiments (right side covered with Advance ${ }^{\circledR}$ black PVC tape and left side, uncovered) and $\mathbf{b}$ conditions of temperature $\left({ }^{\circ} \mathrm{C}\right)$ and $\mathrm{RH}(\%)$ inside the humidity chamber during the experiments recorded with the data logger 


\section{Results}

\section{Wood density}

The oven-dry densities of the wood samples, calculated from the weight and dimensions of the specimens, are presented in Table 3, with the average and standard deviations shown. The low variation in the density values, given by the low $\mathrm{COV}$, highlights the homogeneity of the sample densities, indicating that the mean value of $430 \mathrm{~kg} / \mathrm{m}^{3}$ is a representative value for all the specimens.

\section{Surface temperature rise}

A typical thermal image captured during an experiment is shown in Fig. 3a. The image shows the transverse surface of a specimen, and anatomical features, such as the growth rings, are clearly visible on the right-hand side of the image; the distinction suggests variations in temperature throughout the wood material. The right-hand side of the image shows the surface covered with black PVC tape which was used later as an impermeable coating to serve as a reference surface to illustrate the stability of the temperature conditions inside the humidity chamber during the experiments (see Fig. 4c).

Figure 4 shows that the surface temperature-measured as the average temperature over the region of interest, including early wood and late wood-increases as a function of time, $\Delta T(t)$, when wood, initially in the oven-dried state (i.e. $0 \% \mathrm{MC}$ ) is placed inside the humidity chamber and is suddenly exposed to $95 \% \mathrm{RH}$. Temperature rises on the radial, tangential and transverse surfaces are shown in Fig. $4 \mathrm{a}-\mathrm{c}$, respectively. The surface temperature increase of wood is given by $\Delta T(t)=T(t)-T_{i}(0)$, where $T(t)$ is the surface temperature recorded by the camera and $T_{i}(0)$ is the initial temperature of the sample surface recorded by the camera at $t=0$. The emissivity values for the wood sample are taken from the literature (Table 2) and set to 0.95 (see 'Discussion' section).

The black curve is the average of the 10 replicates tested, whilst the grey curve above is the average + the standard deviation and the grey curve below is the average - the standard deviation. Table 4 summarises, for each of the three surfaces measured, the maximum temperature increase, $\Delta T_{\max }$, and the time needed to attain this value, $t_{\max }$.

Table 3 Mean, standard deviation and COV values for the samples densities (10 parallel samples for each direction)

\begin{tabular}{lcrcc}
\hline & Transverse & Radial & Tangential & All samples \\
\hline Mean $\left(\mathrm{kg} / \mathrm{m}^{3}\right)$ & 428.1 & 432.2 & 429.7 & 430.0 \\
$\mathrm{SD}$ & 12.4 & 22.6 & 16.4 & 17.4 \\
$\mathrm{COV}(\%)$ & 2.9 & 5.2 & 3.8 & 4.0 \\
\hline
\end{tabular}






Fig. $4 \Delta T(t)$ recorded for (a) radial, (b) tangential and (c) transverse samples for the first 10 min of experiments and $T(t)$ for longer time period $(\mathbf{d})$. A reference sample fully covered with Advance ${ }^{\circledR}$ PVC black tape is also presented in (c)

Table 4 Mean, standard deviation and COV values for $\Delta T_{\max }$ and $t_{\max }$ (10 replicates for each direction)

\begin{tabular}{|c|c|c|c|c|c|c|}
\hline & \multicolumn{3}{|l|}{$\Delta T_{\max }\left({ }^{\circ} \mathrm{C}\right)$} & \multicolumn{3}{|l|}{$t_{\max }(\mathrm{s})$} \\
\hline & Transverse & Radial & Tangential & Transverse & Radial & Tangentia \\
\hline Mean & 3.6 & 1.4 & 1.5 & 282 & 48 & 48 \\
\hline SD & 0.2 & 0.3 & 0.3 & 92 & 4 & 6 \\
\hline $\operatorname{COV}(\%)$ & 4.7 & 19.5 & 22.0 & 33 & 9 & 13 \\
\hline
\end{tabular}

\section{Discussion}

\section{Anisotropic surface temperature change}

The form of the $\Delta T(t)$ curves (Fig. 4) was found to be consistent for each of the ten replicates tested on each of the three wood surfaces (i.e. radial, tangential and transverse). However, the results from the transverse surfaces were noted to differ significantly from those of the radial and tangential surfaces (Fig. 4, Table 4). As may be seen, the surface temperature on the radial and tangential surfaces rises more rapidly (mean $t_{\max }=48 \mathrm{~s}$ ), but reaches a lower maximum temperature (mean $\Delta T_{\max }$ of $1.4-1.5^{\circ} \mathrm{C}$ ) than the transverse surface for which the rise is higher (mean 
$\Delta T_{\max }$ of $3.6^{\circ} \mathrm{C}$ ) and takes longer to reach its peak value (mean $t_{\max }=282 \mathrm{~s}$ ). The results of Kraniotis et al. (2016) on the tangential surface of spruce heartwood are of the same order of magnitude as the current findings, albeit the behaviour was observed to be closer to that seen on the transverse surfaces of the specimens tested in this present work $\left(t_{\max }=500 \mathrm{~s} / \Delta T_{\max }=2.1{ }^{\circ} \mathrm{C}\right)$. This difference is most probably attributable to the different experimental procedure adopted by Kraniotis and co-workers, who measured the surface temperature change on wood that had a nonzero initial moisture content and under conditions of slowly increasing relative humidity, changing from 25 to $90 \%$ over the course of $12 \mathrm{~h}$. Further, the work of Kraniotis et al. (2016) was on spruce heartwood, which would doubtlessly behave differently to the Scots pine used in this study that contained both sapwood and heartwood, whilst the specimens also differed in size which would have undoubtedly affected the mass and heat transfer characteristics. These findings suggest some interesting possibilities for using wood to help passively lower the heating (or cooling) energy used in buildings. Typically solid wood panelling, for instance, is installed with the tangential surface (or a combination of tangential and radial surfaces) exposed to the room in which it is situated. The wood is also generally coated, which may prevent the exchange of moisture between wood and the surroundings. These results suggest that by exposing the 'end grain' of the wood, i.e. the transverse surface, together with the use of coatings that do not hinder the exchange of moisture (Lozhechnikova et al. 2015), the potential for utilising the heat of sorption phenomenon could be maximised.

\section{Influence of wood structure}

For the interpretation of the results, the following assumption is made; the main direction of propagation of moisture and heat is normal to the exposed surface. Moisture and heat transfer are thus mainly in the longitudinal direction in specimens with the transverse surface exposed (and naturally either in the radial or tangential directions in the others) (Fig. 2b).

Anatomical knowledge of the structural shape and arrangement of cells in wood (Comstock 1970) helps us to understand the higher temperature rise on the transverse surface. In the longitudinal direction, water vapour can flow more readily and for greater distances into the wood structure in the gaseous phase before adsorbing onto the surfaces of the cell wall polymers. Softwood tracheids can be several millimetres in length, so that even when cut across, the lumens may be more than a millimetre in length, allowing for rapid adsorption on to a relatively large surface area. In contrast, there is more resistance to moisture movement in the radial and tangential directions, since flow is impeded by the cell wall (Perré 2015) and the necessity for vapour in the cavities to flow through the connecting pits. Moisture diffusion coefficients are consequently higher in the longitudinal direction $\left(3.10^{-5} \mathrm{~cm}^{2} / \mathrm{s}\right.$ at $25{ }^{\circ} \mathrm{C}$ ) than in the transverse $\left(5.10^{-7} \mathrm{~cm}^{2} / \mathrm{s}\right.$ at $25^{\circ} \mathrm{C}$ ) (values given by Siau 1984 for oven-dry pine of similar $500 \mathrm{~kg} / \mathrm{m}^{3}$ density to that used in the present study, Table 3). Therefore, the more significant temperature rise on the transverse surface is a logical consequence of the fact that water is adsorbed, flows 
and forms H-bonds more easily in the longitudinal direction where the sorption sites are anatomically more accessible in wood.

As observed by Comstock (1970), the higher variability of the results on the radial and tangential surfaces might be due to practical sampling matters, in that no perfectly radial or tangential surfaces can be achieved on cubic specimens. In such cases, the different grain angles can vary from one sample to another adding heterogeneous features to the material structure, which is not the case for transverse samples where the slope of the grain can be truly longitudinal, especially for such small surface dimensions $(50 \times 50 \mathrm{~mm})$.

\section{Assessment of experimental errors}

The accurate and reliable measurement of surface temperature, under known conditions of relative humidity and temperature and defined material parameters, such as moisture content and exposed anatomical surface, is essential if the potential of the latent heat of sorption is to be fully exploited in reducing energy demands in buildings and to be incorporated into building physics models.

\section{Stability of conditions within humidity chamber}

The surface temperature recorded on the reference sample, in which adsorption was prevented by a covering of impermeable tape (Fig. 4c), provides confirmation that the internal conditions within the humidity chamber remained constant throughout the experiment. This strongly suggests that the results obtained on the wood sample surfaces represented real temperature changes, despite the limitations of the thermographic method, which are discussed below.

\section{Influence of camera accuracy}

By using relative values $(\Delta T)$, the accuracy of the camera $\left( \pm 2{ }^{\circ} \mathrm{C}\right.$ given by the manufacturers, FLIR) is considered here to be offset, given the stability of the measurements obtained from one point to another.

\section{Influence of emissivity}

The choice of wood emissivity was carefully considered during the experiments in order to ensure that the temperature rise recorded was not an artefact due to any change of emissivity with the moisture content in wood during the experiments. The median value from the literature for softwood species in the corresponding wavelength region (emissivity $=0.95$, Dupleix et al. 2013) was chosen given the fact that wood emissivity increases with the amount of moisture in wood, and the assumption is made that wood material near the surface might equilibrate almost immediately with the surrounding $\mathrm{RH}(90 \%)$ to reach a moisture content near to the saturated state (neglecting the surface resistance, Siau 1984). The latter assumption also allows us to neglect the influence of changes in the wood moisture on emissivity in the same way as the influence of changes in the surface temperature of 
Fig. 5 Effect of emissivity on temperature simulated with FLIR Tools software. Example of a transverse sample

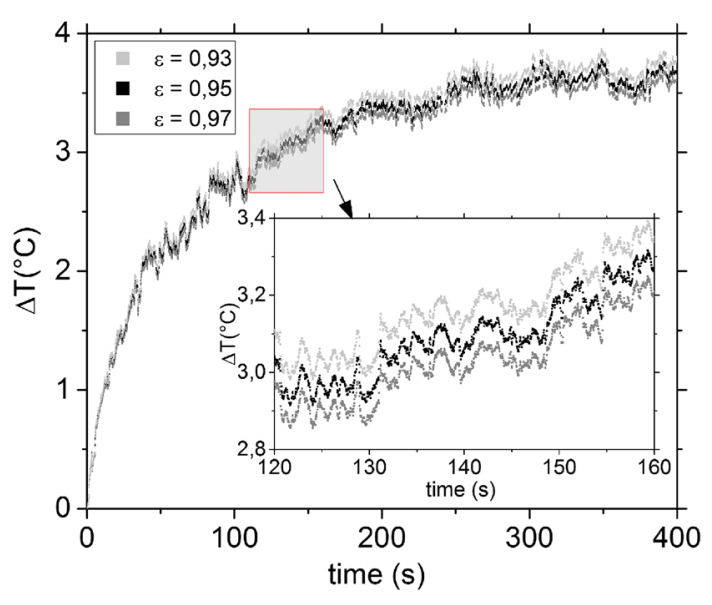

wood on emissivity is neglected because of the small increase recorded (a couple of degrees Celsius). The validity of these assumptions is confirmed in Fig. 5, which shows the sensitivity of wood surface temperature to changes in emissivity value. As may be observed a change in emissivity of \pm 0.02 , a variation, which might be expected to occur due to changes in moisture content, for example, results in only very slight changes (less than $0.01{ }^{\circ} \mathrm{C}$ ) in the measured temperature.

\section{Conclusion}

The adsorption of water in oven-dried wood generates a surface temperature increase of several degrees Celsius, which is recordable by thermal imaging. This phenomenon - the heat of sorption-arises because of the phase change of water from vapour to 'bound' water at the sorption sites in the wood cell wall. The experimental results presented here highlight the anisotropy of the surface temperature rise on the surface of wood due to heat of sorption. The transverse surface of Scots pine wood can undergo a temperature increase of between 3 and $4{ }^{\circ} \mathrm{C}$ when exposed to high humidity (95\%) conditions, whereas the temperature rise on the radial and tangential surfaces was more modest at around 1 to $2{ }^{\circ} \mathrm{C}$, though the maximum temperature was reached rather quickly, and quicker than on the transverse surface. These results validate the ability of the experimental protocol developed here to provide source data useful for calculating the heat of sorption (in terms of unit of energy per mass of wood released) and modelling the energetic impact of wooden surfaces in building interiors. Additional work is ongoing in this respect. Further work studying the heat of sorption on wood coated with different materials would be beneficial in the practical use of this phenomenon in interior design, to benefit the future development of the application of wood in buildings.

Acknowledgements This work was supported by the Wood Life project [2013-2017] funded by Aalto University within the framework of the Aalto Energy Efficiency Programme (AEF). 


\section{References}

Avdelidis NP, Moropoulou A (2003) Emissivity considerations in building thermography. Energ Build 35:663-667

Avramidis S (1997) The basics of sorption. In: Proceedings of international conference of COST action E8: mechanical performance of wood and wood products: wood-water relations, pp 1-16

Barreira E, de Freitas VP (2007) Evaluation of building materials using infrared thermography. Constr Build Mater 21:218-224

Brueckner C, Nore K, Nyrud AQ (2012) Investigating latent heat exchange of untreated panels. In: Proceedings of the 8th meeting of the Northern European network for wood science and engineering (WSE), Kaunas, Lithuania, 13-14 Sept, pp 70-78

Comstock GL (1970) Directional permeability of softwoods. Wood Fiber Sci 1(4):283-289

Dupleix A, Meneses DDS, Hughes M, Marchal R (2013) Mid-infrared absorption properties of green wood. Wood Sci Technol 47(6):1231-1241

Engelund ET (2011) Wood-water interactions. Dissertation, Technical University of Denmark

Engelund ET, Thygesen LG, Svensson S, Hill CA (2013) A critical discussion of the physics of woodwater interactions. Wood Sci Technol 47(1):141-161

FLIR Systems, Inc (2013) FLIR e-series datasheet, 3591 Rev (09/13). Document identity Publ. No.: 64501-0302

Gaussorgues G (1999) La thermographie infrarouge: principes-technologie-applications (Infrared thermography: principles-technology-applications). Technique et Documentation, Paris [in French]

Hill CAS, Norton A, Newman G (2010) The water vapor sorption behavior of flax fibers-Analysis using the parallel exponential kinetics model and determination of the activation energies of sorption. J Appl Polym Sci 116(4):2166-2173

Hofstetter K, Hinterstoisser B, Salmén L (2006) Moisture uptake in native cellulose-the roles of different hydrogen bonds: a dynamic FT-IR study using deuterium exchange. Cellulose 13(2):131-145

Holcroft N, Shea A (2014) Heat of sorption and moisture buffering properties of building insulation materials. In InCIEC 2013. Springer, Singapore, pp 649-661

Kollmann FF, Côté WA Jr (1968) Principles of wood science and technology. Vol. I. Solid wood. Springer, Berlin

Kraniotis D, Nore K, Brückner C, Nyrud AQ (2016) Thermography measurements and latent heat documentation of Norwegian spruce (Picea abies) exposed to dynamic indoor climate. J Wood Sci 62(2):203-209

Leuk P, Schneeberger M, Hirn U, Bauer W (2015) Heat of sorption: a comparison between isotherm models and calorimeter measurements of wood pulp. Dry Technol 34(5):563-573

Lopez G, Basterra LA, Acuna L, Casado M (2013) Determination of the emissivity of wood for inspection by infrared thermography. J Nondestruct Eval 32(2):172-176

Lozhechnikova A, Vahtikari K, Hughes M, Österberg M (2015) Towards energy efficiency through an optimized use of wood: the development of natural hydrophobic coatings that retain moisturebuffering ability. Energy Build 105:37-42

Marsh KN (1987) Recommended reference materials for the realization of physicochemical properties. Blackwell, Oxford

Osanyintola OF, Simonson CJ (2006) Moisture buffering capacity of hygroscopic building materials: experimental facilities and energy impact. Energy Build 38(10):1270-1282

Perré P (2015) Physique et mécanique du bois (Physics and mechanics of wood). Ed. Actes Sud/ Fondation d'Entreprises Hermès, pp 52-70. ISBN 978-2-330-05329-1 (in French)

Salmén L (1997) The sorption behaviour of wood. In: Proceedings of international conference of COST action E8: mechanical performance of wood and wood products: wood-water relations, pp 33-44

Siau JF (1984) Transport processes in wood. Springer, Berlin

Simón C, Esteban LG, de Palacios P, Fernández FG, Martín-Sampedro R, Eugenio ME (2015) Thermodynamic analysis of water vapour sorption behaviour of juvenile and mature wood of Abies alba Mill. J Mater Sci 50(22):7282-7292

Skaar C (1988) Wood-water relations. Springer, Berlin

Suleiman BM, Larfeldt J, Leckner B, Gustavsson M (1999) Thermal conductivity and diffusivity of wood. Wood Sci Technol 33:465-473

Time B (1998) Hygroscopic moisture transport in wood. Dissertation, Norwegian University of Science and Technology 